\title{
The aetiology of mirror writing: a new hypothesis
}

\author{
K TASHIRO, A MATSUMOTO, T HAMADA, F MORIWAKA \\ From the Division of Neurology, Department of Neurosurgery, Hokkaido University School of Medicine, \\ Sapporo, Japan
}

SUMMARY Twenty-eight cases of mirror writing were seen during a period of three and a half years. These consisted of 12 patients with essential tremor, nine with Parkinson's disease, three with spino-cerebellar degeneration and four other cases. There were no cases of hemiparesis, aphasia, apraxia, agnosia or confusion. Fragmentary reversals were excluded from this study. Since essential tremor, Parkinsonian tremor and cerebellar tremor can be abolished by a stereotaxic produce applied to the thalamus, a common neural pathway via the thalamic nuclei may exist in these disorders. The existence is therefore proposed of some neural mechanism that controls the higher cerebral function of writing via the thalamus.

Mirror writing can be defined as writing which runs in an opposite direction to the normal, and in which each individual letter is also reversed. The resultant script cannot therefore be read by most people unless it is held up in front of a mirror. Historically, the most famous example of mirror writing is that produced by Leonardo da Vinci.

In 1926, Critchley proposed the aetiological classification of mirror writing. ${ }^{1}$ First, he listed the appearance of mirror writing in a left handed script in certain cases of right hemiplegia. Many of the cases reported by subsequent authors fall into this category. He also mentioned cases of mirror writing among certain normal children while they are learning to write, among a number of backward children and feeble-minded adults, among people with congenital word blindness, among right-handed writers who are dextrally switched, and among patients suffering from Little's disease. At the same time, normal individuals can, as Critchley pointed out, write in mirror fashion with the right or left hand in certain experimental conditions.

The aim of this report is to document the discovery of a high incidence of mirror writing among cases of essential tremor, Parkinson's disease and some cerebellar disorders, and to propose a new aetio-

Address for reprint requests: Kunio Tashiro, MD, Division of Neurology, Department of Neurosurgery, Hokkaido University School of Medicine, Kita-15, Nishi-7, Kita-Ku, Sapporo 060, Japan.

Received 19 August 1986 and in final revised form 20 May 1987. Accepted 22 May 1987. logical hypothesis for the occurrence of mirror writing.

\section{Patients and methods}

\section{Patients (fig 1, case 1 in table 2)}

Our own interest in this problem was aroused by observation of a 54 year old right-handed man with essentialo tremor, who exhibited complete mirror writing ability with his left hand. With his right hand he wrote from left to right in kanji (Chinese characters), and he drew a clock face; these were unskilfully written and drawn because of his actiono tremor. When he was instructed to write with the left hand, however, he wrote kanji from right to left in mirror fashion without any hesitation. He did not even recognise his own mirror writing. In the case of the clock face, not only the numerals, but also the position of the clock digits were reversed.

\section{Prospective Evaluation of the Clinical Cases}

Following our discovery of this initial case, we decided to evaluate the incidence of mirror writing in cases of neurological disorders which included not only essential tremor, but also Parkinson's disease, spinocerebellar degeneration, cerebrovascular disease, and various other neurological complaints, on the basis of work in an outpatients clinic. In addition, 258 medical and nursing students were asked to cooperate by writing their names with both right and left hands without any further suggestions. Although these students were much younger than the patients and were therefore unsuitable as perfectly exact age and sex matched controls, they can nevertheless be used as examples of how normal subjects write with their left hands.

The mirror writing we report on here was, of course, induced mirror writing, which is somewhat different from the many types of case with spontaneous mirror writing classified by Critchley. Yet in every case, mirror writing was demonstrated when our patients were instructed to write letters with their left hands. 
The aetiology of mirror writing: a new hypothesis

Table 1 Incidence of mirror writing among patients with neurological disorders and controls

\begin{tabular}{|c|c|c|c|c|}
\hline Diagnosis & $\begin{array}{l}\text { Number of } \\
\text { cases }\end{array}$ & $\begin{array}{l}\text { Complete } \\
\text { mirror writing }\end{array}$ & $\begin{array}{l}\text { Partial } \\
\text { mirror writing }\end{array}$ & $\begin{array}{l}\% \text { of complete } \\
\text { mirror writing }\end{array}$ \\
\hline $\begin{array}{l}\text { Essential tremor } \\
\text { Parkinson's disease } \\
\text { Spinocerebellar degeneration } \\
\text { Cerebrovascular disease } \\
\text { Others } \\
\text { Normal control }\end{array}$ & $\begin{array}{r}65 \\
66 \\
35 \\
23 \\
63 \\
258\end{array}$ & $\begin{array}{r}12 \\
9 \\
3 \\
1 \\
3 \\
0\end{array}$ & $\begin{array}{l}4 \\
7 \\
2 \\
2 \\
5 \\
0\end{array}$ & $\begin{array}{l}18.5 \% \\
13.6 \% \\
8.6 \% \\
4.3 \% \\
4.8 \% \\
0 \%\end{array}$ \\
\hline Total & 510 & 28 & 20 & \\
\hline
\end{tabular}
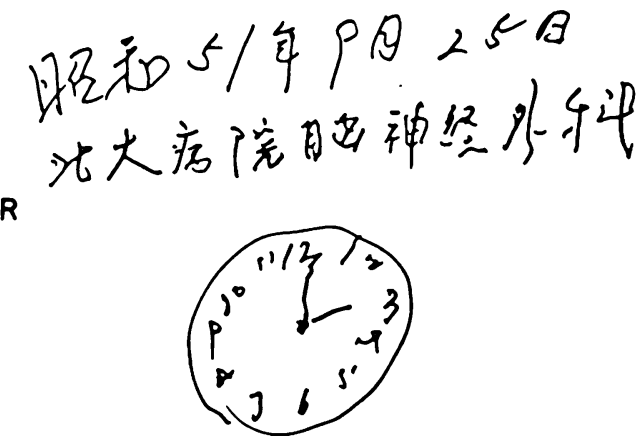

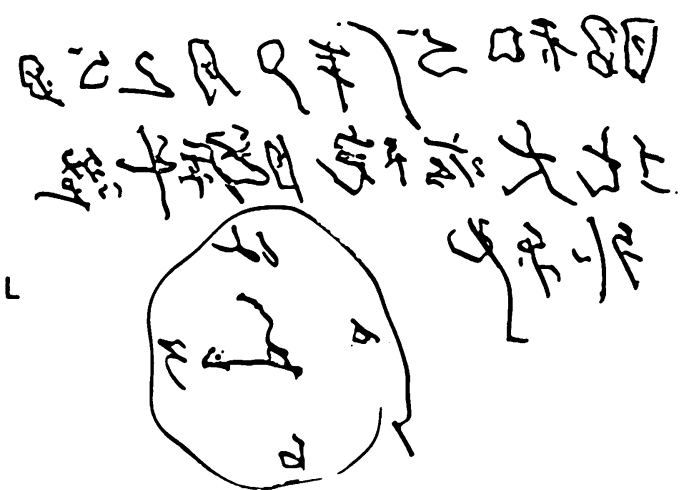

Fig 1 A 54 year old right-handed man with essential tremor. $R$ indicates right-handed script, while $L$ indicates left-handed script. Arrow indicates the direction of handwriting.

Table 2 Clinical diagnosis and characteristics of 28 cases with complete mirror writing

\begin{tabular}{|c|c|c|c|c|c|c|c|}
\hline Case & Age & Sex & Diagnosis & Handedness & $\begin{array}{l}\text { Recognition of } \\
\text { mirror writing }\end{array}$ & $\begin{array}{l}\text { Position of } \\
\text { clock-digit }\end{array}$ & $\begin{array}{l}\text { Fragmentary reversals } \\
\text { (from } L \text { to } R \text { ) }\end{array}$ \\
\hline 1 & 54 & $\mathbf{M}$ & Essential tremor & $\mathbf{R}$ & - & $\mathbf{R} \rightarrow \mathbf{N}$ & - \\
\hline 2 & 64 & $\mathrm{~F}$ & Essential tremor & $\mathbf{R}$ & - & $\mathbf{R}$ & + \\
\hline 3 & 64 & $\mathrm{~F}$ & Essential tremor & $\mathbf{R}$ & - & & $*$ \\
\hline 4 & 64 & $\mathbf{M}$ & Essential tremor & $\mathbf{R}$ & - & $\mathbf{R} \rightarrow \mathbf{N}$ & $*$ \\
\hline 5 & 61 & $\mathrm{~F}$ & Essential tremor & $\mathbf{R}$ & - & $\mathbf{N}$ & + \\
\hline 6 & 47 & $\mathbf{F}$ & Essential tremor & $\mathbf{R}$ & + & $\mathbf{N}$ & - \\
\hline 7 & 60 & $\mathrm{~F}$ & Essential tremor & $\mathbf{R}$ & - & $\mathbf{N}$ & + \\
\hline 8 & 64 & M & Essential tremor & $\mathbf{R}$ & + & $\mathbf{N}$ & - \\
\hline 9 & 65 & $\mathrm{~F}$ & Essential tremor & $\mathbf{R}$ & - & $\mathbf{R}$ & * \\
\hline 10 & 73 & M & Essential tremor & $\mathbf{R}$ & + & $\mathbf{N}$ & + \\
\hline 11 & 75 & $\mathbf{M}$ & Essential tremor & $\mathbf{R}$ & + & $\mathbf{R}$ & * \\
\hline 12 & 74 & $\mathbf{F}$ & Essential tremor & $\ddot{R}$ & - & $\mathbf{N}$ & $*$ \\
\hline 13 & 47 & $\mathrm{~F}$ & Parkinson's disease & R & + & $\mathbf{R}$ & - \\
\hline 14 & 67 & $\mathrm{~F}$ & Parkinson's disease & L & - & $\mathbf{R}$ & * \\
\hline 15 & 70 & $\mathbf{F}$ & Parkinson's disease & $\mathbf{R}$ & - & $\mathbf{N}$ & * \\
\hline 16 & 60 & $\mathrm{~F}$ & Parkinson's disease & $\mathbf{R}$ & - & $\mathbf{N} \rightarrow \mathbf{R}$ & + \\
\hline 17 & 64 & $\mathrm{~F}$ & Parkinson's disease & $\mathbf{R}$ & - & $\mathrm{N}$ & + \\
\hline 18 & 70 & $\mathrm{~F}$ & Parkinson's disease & $\mathrm{R}$ & - & $\mathbf{N}$ & + \\
\hline 19 & 41 & $\mathbf{F}$ & Parkinson's disease & $\mathrm{R}$ & - & * & * \\
\hline 20 & 52 & $\mathrm{~F}$ & Parkinson's disease & $\mathbf{R}$ & + & $\mathbf{N}$ & + \\
\hline 21 & 65 & $\mathbf{F}$ & Parkinson's disese & $\mathbf{R}$ & - & $\mathbf{R}$ & + \\
\hline 22 & 68 & $\mathbf{F}$ & SCD & $\mathbf{R}$ & - & $\mathbf{N}$ & + \\
\hline 23 & 55 & M & SCD & $\mathbf{R}$ & - & $\mathbf{R}$ & - \\
\hline 24 & 55 & M & SCD & L & - & $\mathbf{R}$ & + \\
\hline 25 & 47 & $\mathbf{F}$ & 4th vent. $t$. & $\mathbf{R}$ & - & $\mathbf{R} \rightarrow \mathbf{N}$ & + \\
\hline 26 & 39 & $\mathrm{~F}$ & Tension headache & $\mathrm{L} \rightarrow \mathrm{R}$ & + & $\mathbf{N}$ & + \\
\hline $\begin{array}{l}27 \\
28\end{array}$ & $\begin{array}{l}48 \\
57\end{array}$ & $\begin{array}{l}\mathbf{M} \\
\mathbf{M}\end{array}$ & $\begin{array}{l}\text { Writer's cramp } \\
\text { CVD }\end{array}$ & $\vec{L} \rightarrow R$ & + & $\stackrel{\mathbf{N}}{\mathbf{N}}$ & + \\
\hline & & & - I ft & ht & ${ }^{*}$ :not examin & & \\
\hline
\end{tabular}


Case 7 Essential tremor

$$
\text { Fig } 2 \text { A } 60 \text { year old right-handed woman with essential tremor. }
$$
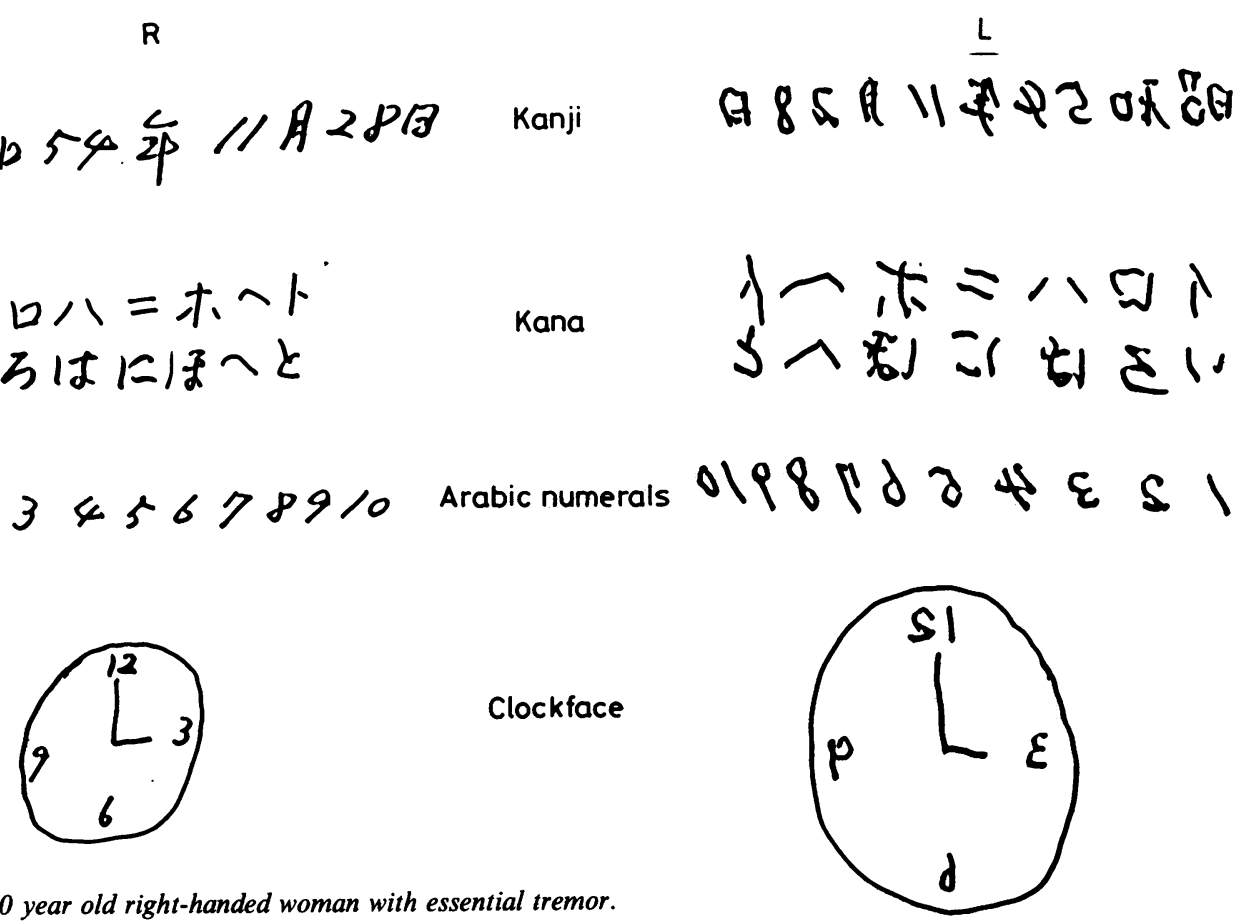

\section{Results}

We found altogether 28 cases of complete mirror writing during the period of 3 and a half years (table 1). The patient comprised 12 cases of essential tremor, nine of Parkinson's disease, three of spinocerebellar degeneration, one of cerebrovascular disease, and three others from among 63 adult neurology patients suffering from complaints such as headache, myopathy, neuropathy, and so on who acted as a control group during the same period. A high incidence of complete mirror writing was found in cases of essential tremor, Parkinson's disease and spinocerebellar degeneration, comprising $18.5 \%$, $13.6 \%$ and $8.6 \%$, respectively. On the other hand, none of the 258 students showed any sign of mirror writing. It is well known that certain normal children who are learning to write exhibit fragmented reversal of letters either with their left or right hands. Some of our patients showed similar fragmented reversals, and these are listed as partial mirror writing in table 1. The significance of this partial mirror writing is another important subject, but we have excluded these partial reversals from our present analyses in order to concentrate upon complete mirror writing only.
Representative cases

We discuss in detail three representative cases, and one unique case.

Case 7 A 60 year old right-handed woman had essential tremor. The sample of her left-hand script (fig 2) written in mirror fashion shows kanji (or Chinese characters), kana (or the Japanese alphabet; this has two types: kata-kana and hira-kana, both used in this example), as well as Arabic numerals. In this patient, the position of the clock-digits is normal; only the numerals are reversed.

Case 13 was another left-handed example of mirror writing by a 47 year old right-handed woman with Parkinson's disease (fig 3). Her name, sentences in English, alphabetic letters and Arabic numerals are mirrored, as well as Japanese kanji, hira-kana and kata-kana words. The clock-face is also completely reversed.

Case 20 was another example of a patient with Parkinson's disease (fig 4). Here, the upper half of the fig shows smooth complete mirror writing from right to left with the left hand. In the lower half the patient is trying to write normal letters and numerals from left to right, but her script is poor with many fragmented reversals; these are indicated by arrowheads. This example clearly suggests that for this 
$R$

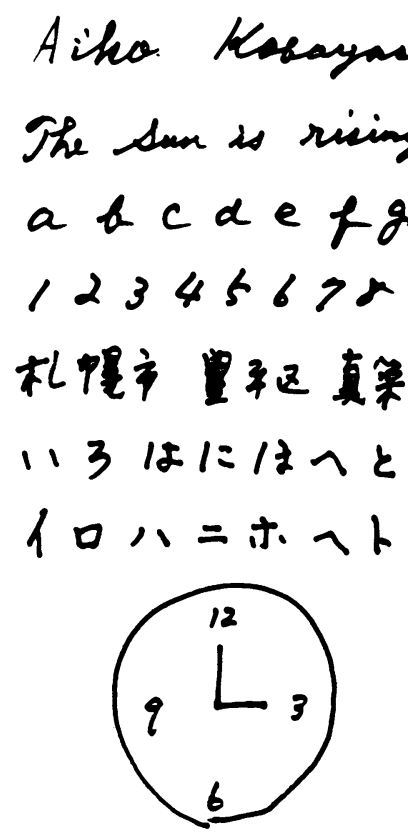

Name

English

Alphabet

Arabic numerals

Kanji

Kana

Clockface
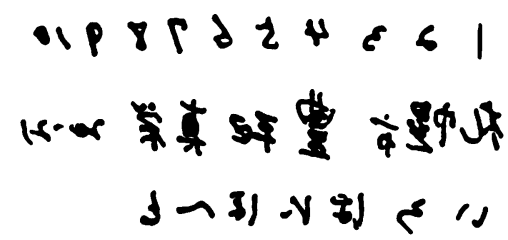

Fig 347 year old right-handed woman with Parkinson's disease.

patient mirror writing is more natural with the left hand in the direction from right to left than ordinary writing with the left hand. In most of the cases (14 out of 19 cases in table 2), when the patients were asked to write normal letters and numerals in the ordinary direction, that is from left to right with their left hands, they wrote awkwardly and slowly, with many fragmented reversals.

Case 28 was a 57 year old right-handed man with right cerebral infarction in the territory of the middle cerebral arteries. Although a CT scan revealed a marked low density area, he showed almost no hemiparesis when his handwriting was tested. With his left hand he wrote his name in kanji and Roman letters (fig 5) as well as alphabets, numerals, and kana words in a very skilful manner. He knew he wrote them in mirror fashion, and mentioned that the faculty of mirror writing seemed to have existed for hundreds of years. Since the many reported cases of mirror writing in cerebrovascular disease involve the left cerebral hemisphere with right hemiparesis, this case is therefore unique and should be considered separately.
Summary of 28 cases with sinistral mirror writing A summary of the 28 cases with mirror writing is shown in table 2 . There were 12 cases of essential tremor; the age of the patients varied from 47 to 75 , average age $63 \cdot 8$. They were five men and seven women, and all were right-handed. Eight out of the 12 cases did not even recognise that they wrote a mirror script, and simply remarked that they wrote poorly. The position of clock-digits was repeatedly reversed in four cases, while a correction to the normal position on the subsequent trials was observed in two cases. Writing from left to right with the left hand, which was tested in seven cases, was slow and clumsy in every case, while fragmentary reversals were seen in four cases. There were eight cases of Parkinson's disease, whose age ranged from 41 to $70 \mathrm{yrs}$, average age 59.6. All were women, and only one was lefthanded. Seven patients failed to recognise their mirror writing. The reversed position of clock-digits was seen in three cases, and one case made a correction on subsequent examinations. Again, fragmentary reversals were observed in five out of the six cases tested. There were three cases of spino- 
Case 20 Parkinson's disease

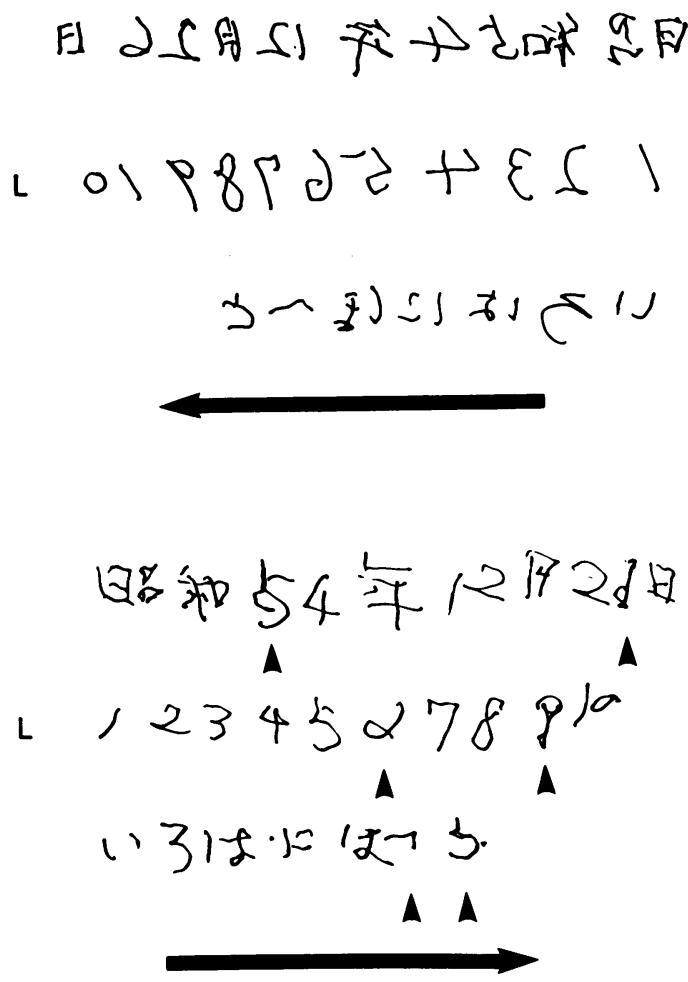

Fragmentary reversals $(+)$

Fig 4 A 52 year old right-handed woman with Parkinson's disease. The mirror writing was performed without any difficulty when she was writing from right to left with her left hand (upper example). However, there are many fragmentary reversals (arrow-heads) when she is writing ordinary letters and numerals from left to right (lower example).

cerebellar degeneration, and one case of an epidermoid tumour on the fourth ventricle, all of which suffered from cerebellar ataxia.

Sufferers from tension headache and writer's cramp were both natural left-handers, who had been corrected to right-handedness during childhood. A final case with cerebrovascular disease needs to be considered; this was a man who probably had his own faculty for mirror writing, and his vascular disease had merely given him the chance to discover his talent.

\section{Discussion}

Whenever we discuss this interesting problem of mirror writing, we always have to come back to Leonardo da Vinci, whose mirror writing is the most
Case 28 CVD

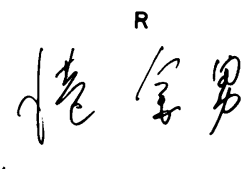

Lanere Munoto

$$
\begin{aligned}
& \text { abose } \\
& 1234567891^{\circ}
\end{aligned}
$$

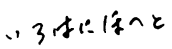

$$
\begin{aligned}
& \text { har }=t \text { t }
\end{aligned}
$$
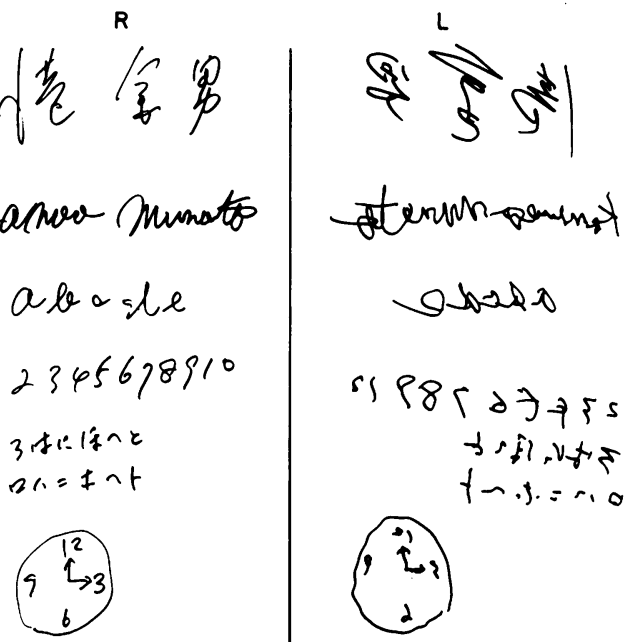

$\sin \rightarrow 20$

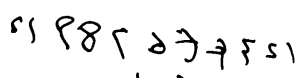

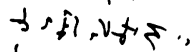
tand $=-10 y$

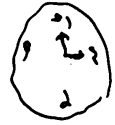

Fig 5 A 57 year old right-handed man with right cerebral infarction. Excellent mirror writing can be observed in his left-handed script.

famous example in history. Why he wrote all his letters in mirror fashion, ${ }^{2}$ however, remains extremely controversial. Most people believe that it was because he was naturally a left-handed writer and painter. Capener, however, insists that da Vinci was essentially right-handed, and that an accident which crippled his right hand in his early life might well have led him to begin to use his left hand, and that he consequently found it most easy to write in mirror fashion. ${ }^{3}$ Some authors attribute his use of the left hand to a stroke causing right hemiparesis. ${ }^{1,4} \mathrm{He}$ only suffered from this stroke in 1517 , however, 2 years before his death, and this can not therefore be an explanation for his mirror writing. An excellent discussion concerning Leonardo da Vinci's handwriting has been published by Schott, ${ }^{5}$ who concluded that Leonardo was left-handed and that his language skills were lateralised to the right hemisphere.

Another interesting article has been written by Allen, ${ }^{6}$ who accidentally discovered his own faculty of mirror writing at the age of 13 years. Leonardo da Vinci and case 28 in our series might belong to the category of natural mirror writer, like Allen himself.

The aetiological classification of mirror writing is well summarised by Critchley in 1926, and is still valid in the clinical study of mirror writing.

Our initial case was a right-handed man with essential tremor. When we saw this patient, we first thought that the mirror writing was an accidental coincidence. However, as we started to come across more and more mirror writers among the cases of 
essential tremor and Parkinson's disease, we were forced to consider that this could not be simply coincidental, and that it required some common mechanisms. It has been observed that essential tremor and Parkinson's disease frequently occur in the same patient and that these disorders may be related either pathogenetically or genetically, ${ }^{7}$ while a recent systematic study of this association between essential tremor and Parkinson's disease in a large number of cases confirms this assumption, ${ }^{8}$ although a completely contrary conclusion has also been drawn by other workers. ${ }^{9}$

Another interesting fact that has recently been noted is a higher incidence of left-handedness among patients with essential tremor, ${ }^{10}$ since the occurrence of mirror writing has a close relationship to lefthandedness.

None of the 28 cases we report suffered from hemiparesis, aphasia, apraxia, agnosia or confusion, nor were the phenomena we observed transient in nature; they were observed repeatedly during the follow-up period, the longest being of over 5 years. Although we still do not know why mirror writing has been discovered so frequently among patients with essential tremor and Parkinson's disease, these associations remain extremely interesting. Nor should we overlook the fact that mirror writing was seen in three cases of spinocerebellar degeneration and one case of a fourth ventricle tumor with cerebellar ataxia. Are there any common factors that will explain the occurrence of mirror writing among patients with these disorders? Recently, Narabayashi and his co-workers proposed that essential, Parkinsonian and cerebellar tremors can be abolished by application of a stereotaxic procedure to the Vim nucleus of the thalamus. ${ }^{11,12}$ This fact suggests that among these disorders there are common neural mechanisms which operate via the thalamus.

The participation of thalamus in higher cerebral function has been discussed in the literature, in cases of "thalamic neglect" in the non-dominant, ${ }^{13}$ and "thalamic aphasia" in the dominant side. ${ }^{14}$ Cases of mirror writing following left thalamic hemorrhages have also been reported recently. ${ }^{15,16}$ In these reports, the mechanism responsible for thalamic neglect or thalamic mirror writing is attributed to the impaired arousal-activation process of the thalamus; the existence of thalamic aphasia remains controversial, however. Nevertheless, these facts suggest that the thalamus must be playing an important role in and must contribute to the higher cortical functions.

Only rarely, as we have said, does a natural mirror writer such as Leonardo da Vinci, Allen or case 28 in this series exist. In normal individuals, however, no mirror writing can be found with either right or left handed script. The appearance of mirror writing in cases of sufferers from right hemiplegia with left hemispheric lesions, or among younger children whose cerebral dominance has not been established, has been well-documented, but the higher incidence of mirror writing among cases of essential tremor, Parkinson's disease and cerebellar ataxias has not been described in the past. If we could postulate the existence of some neural mechanism controlling the higher cerebral function of writing via the thalamus, then we might be able to explain our new observations. We do not know why some of our patients failed to recognise their own mirror writing, but we suggest that these phenomena may also be related to the thalamic mechanisms.

In conclusion, we wish to add two new categories to Critchley's aetiological classification of mirror writing (table 3).

Table 3 Aetiological classification of mirror writing (modified from Critchley 1926)

(1) Spontaneous

(a) Certain cases of right hemiplegia (with left hand)

(b) Certain normal children who are learning to write (left and right hand)

(1) Complete mirror writing

(2) Fragmentary reversals

(c) Some backward children and feeble-minded adults, particularly when associated with left-handedness (usually with the left hand)

(d) Cases of congenital word blindness (either hand) (the reversals are usually partial only)

(e) In the left-handed script of sinistrals who have been taught to write with their right hand (under special circumstances)

(f) Cases of Little's disease (left hand)

(2) Experimental

(a) Bi-manual writing

(b) Forehead writing (either hand)

(c) Writing on the under surface of a board (either hand)

(d) During states of inattention or partial obfuscation of consciousness (with left hand)

(1) After blows on head

(2) During hypnosis or in hysterical trance states

(3) Intoxication with alcohol, ether, or cannabis indica

(4) During mental abstraction

*(e) Certain cases of essential tremor, Parkinson's disease, and cerebellar disorders

*Proposed additions by the author. 


\section{References}

1 Critchley M. The significance of mirror writing. Proc $R$ Soc Med 1926;20:397-404.

2 Hart IB. The World of Leonardo da Vinci: Man of Science, Engineer and Dreamer of Flight. Fairfield: $A M$ Kelley, 1977; 192-6.

3 Capener N. Leonardo's left hand. Lancet 1952;ii:813-4.

4 Ireland WW. On mirror-writing and its relation to lefthandedness and cerebral disease. Brain 1881;4:361-7.

5 Schott GD. Some neurological observations on Leonardo da Vinci's handwriting. J Neurol Sci 1979;42:321-9.

6 Allen FJ. Mirror writing. Brain 1896;19:385-7.

7 Critchley M. Observations on essential (heredofamilial) tremor. Brain 1944;72:113-39.

8 Geraghty JJ, Jankovic J, Zetusky WJ. Association between essential tremor and Parkinson's disease. Ann Neurol 1985;17:329-33.

9 Marttila RJ, Rautakorpi I, Rinne UK. The relation of essential tremor to Parkinson's disease. J Neurol Neurosurg Psychiatry 1984;47:734-5.

10 Biary N, Koller W. Handedness and essential tremor.
Arch Neurol 1985;42:1082-3.

11 Narabayashi $\mathrm{H}$, Ohye C. Parkinsonian tremor and nucleus ventralis intermedius of the human thalamus. Desmedt JE ed. Progress in Clinical Neurophysiology. vol. 5, Basel; Karger, 1978: 165-72.

12 Ohye C, Narabayashi $\mathrm{H}$. Physiological study of presumed ventralis intermedius neurons in the human thalamus. J Neurosurg 1979;50:290-7.

13 Watson RT, Valenstein E, Heilman KM. Thalamic neglect. Possible role of the median thalamus and nucleus reticularis in behavior. Arch Neurol 1981; 38:501-6.

14 Benson DF. Aphasia, Alexia, and Agraphia. Clinical Neurology and Neurosurgery Monographs. New York: Churchill Livingstone, 1979:96-8.

15 Mamiya A, Sato M, Tsukahara Y, et al. A case of left thalamic hemorrhage presenting mirror writing. Proceeding of the 4th Japanese Society of Aphasiology. Tokyo, 1980:18 (abstract).

16 Okamoto Y, Nakamura H, Nakajima S, et al. A case of thalamic aphasia with mirror writing. Clin Neurol (Tokyo) 1986;26:654 (abstract). 